\title{
An Interview with
}

\section{Dr. Bernle Warren, Clown} Doctor and Founder of Fools for Health

\section{Bernie Warren and Raymond Chodzinski}

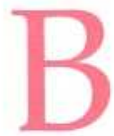

ernie Warren Ph.D. (A.K.A. Dr. Haven't-AClue) is a full professor at the University of Windsor. His expertise and research spans a vast array of interests that relate to wellness, well-being, and the role of the arts in healthcare and education and are reflected in many articles, books, speaking engagements and participation in international symposiums and conferences. In 2001, he was awarded the Alumni Award for Distinguished contributions to University Teaching. His research and practice brings together his training and interest in Eastern martial arts and healing with his Western training in psychology and performing arts. He has worked with severely disabled children, seniors and people with life threatening medical conditions. His work with therapeutic clowns, "Clown-doctors" as he prefers, has been acclaimed as pioneering work in the field of applied medicine and child life specialties. In this interview, I discuss specifically with Dr. Warren about the role of humour and the work of clown-doctors.

\section{Chodzinski:}

What is a clown-doctor and what does your work entail.

\section{Warren:}

A clown-doctor is a specially trained professional artist who works in a therapeutic program within a hospital or other healthcare facility. Clown-doctors interact with patients, families and health care staff in hospital rooms and hallways and visit patients and their families at their bedside. They engage in play with children and adults and try to introduce humour to otherwise sad situations.

Our clown-doctors are all paid professionals and are obliged to act under a strict ethical model of conduct and must agree to confine actions to those behaviours identified and described as under the rubric of what is know as a Clown-doctor.

Unlike clowns who make occasional visits to hospital bedsides merely to 'entertain', professional clown-doctors are trained to provide specific support services to healthcare practitioners and 'therapeutic humour' to patients, their families and the staff who interact with them. At best, they are an accepted part of a health team working together to provide health care services to patients in need.

They employ music, improvised play and the artistry of traditional clowns, (mime, dance, juggling, magic, pratfalls, set gags and routines), and engage patients with short improvised stories and scenes to assist them with personal coping mechanisms and to help them and their families develop positive attitudes and resilience in the face of illness, tragedy and life adversity.
Chodzinski:

What prompted you to start Fools for Health?

\section{Warren:}

My work has always been about personal development. It is and continues to be about wellness and good health and how to attain it and maintain it. I have been involved in various aspects of social work, medicine, dance and drama and of course Eastern martial and healing arts particularly Qigong and Tai Chi.

I believe that if you do not have your health you are hard pressed to concentrate on anything else. Accidents, illnesses, disabilities, various life challenges all threaten personal wellness and quality of life. I have sought ways to assist people to cope with various life pressures and to move forward no matter how desperate or debilitating their situation may be. I believe that humour, and laughter, is an integral aspect in maintaining wellness and resiliency.

Fools for Health was founded in 2001 as an outcome of more than ten years of research into the use of humour in healing culminating in my work with Caroline Simonds and Le Rire Médecin (a clown-doctor company in Paris).

The founding principle that drives Fools for Health is a profound belief that "clowns" can and do provide a form of health care that is so often missing in the hospital environment. For, while doctors, nurses and the rest of the healthcare team usually focus on the parts of the patient that are 'sick', clown-doctors focus on the parts of the patient that are 'well'. Moreover, Clown-doctors make people laugh, but more im- 
portantly, they make them smile. Our motto is a laugh may last for a moment but a smile lingers long after the clown-doctor has left the room.

\section{Chodzinski:}

Who are the clown-doctors? How are they trained?

\section{Warren:}

Our organization, Fools for Health, which is located in Windsor, Ontario, was the first full time professional clown-doctor program in Canada. Initially, we received direct support from the University of Windsor; in 2003, we became a registered charity.

\section{A laugh may last for a} moment but a smile lingers long after the clown-doctor has left the room.

Since 2001, we have employed more than 20 different clowndoctors. Our Clown-doctors have come from a wide range of backgrounds. Most candidates come to us with a degree (some a graduate degree) in music or drama / theatre and some relevant healthcare or special education experience. All must exhibit high levels of empathy, understanding and a willingness to share humour with others.

Once selected we train our Clowns in the art of 'therapeutic humour', how to perform in a healthcare setting and provide them with sufficient knowledge to assist them to be accepted and integral partners in the medical treatment and wellness of patients, hospital visitors, and medical practitioners.

\section{Chodzinski:}

What might I expect to see if I were to follow you throughout a visit to

\section{a hospital?}

\section{Warren.}

First, our clown-doctors always work in pairs; this is referred to as a "clown marriage". We have no set script and so all our work is improvised. As our clowns work across the lifespan, what they do varies with each the skills of the clowns and with each situation, Their interactions with patients, their families and the healthcare staff may range from loud boisterous singing and / or dancing to soft songs accompanied by the use of finger puppets or simply quietly telling a joke or a story at the bedside or nurses station.

On any given day, you might see one or more of us visit a child or senior during a dialysis treatment or visit with an Alzheimer's patient or a child alone in a hospital setting during chemotherapy or who might have suffered major trauma or abuse.

We might bump into a medical staff member who is tired and overworked and requires an emotional boost, We might sit with parents waiting for the results of emergency surgery on a child or loved one or we might comfort a grieving parent or child who has just been advised of a death of a loved one or try to comfort a patient who is at the end of their life.

No patient, or visitor or medical caregiver is immune to laughter and goodwill and our clowns distribute this 'medicine' freely. We view our patients from a wellness perspective. Each day before we get into clown we get notes from the healthcare team about each patient we are to visit. We take on a character that provides us with a persona to act but in fact, we must still be whom we are inside. Our real self-character is what provides us with insight to a patients needs.

We view the power of a smile as 'anti depressant medication'. We try to alleviate the stress resulting from anxiety due to even the simplest of procedures such as being on the receiving end of a needle or a having a cast set. Just simply distracting the patient for a while can be very beneficial to the process. We are not primarily entertainers although we do entertain and have a variety of performing skills but what we do is practice a form of medicine that is designed to 'heal the soul'.

There are not many patients that actually enjoy being in a hospital. We try to take the edge out of the experience and make the environment a good place to be. This is especially true for children. I might add it is important to understand that children who are not patients but who are visiting siblings, parents, grandparents and other loved ones suffer immensely and are often confused and stressed by the experience. Clown-doctors have a wonderful way of enhancing the experience by changing the mood if you will and bringing a sparkle and joy to those with whom we encounter.

\section{Chodzinski:}

I am aware that you conduct information sessions for children. Will you please elaborate?

\section{Warren:}

Yes. While we do not actually go into schools very often, although that might be an excellent proactive venture, we do hold the occasional Health day clinic for kids and we have conducted a Junior Clown-doctor program for Kids 
2:3 Fall 2005

in collaboration with The Hospice of Windsor- Essex County. We also support and we participate in various Healthcare Week activities.

For example, this May Fools for Health Clown-doctors in participation with University of Windsor Faculty of Nursing science Fair hosted groups of grade five and six students in a workshop atmosphere learning about the body and how it works and what makes it sick. 'Laugh doctors' taught children about the

No patient, or visitor or
medical caregiver is
immune to laughter and
goodwill and our clowns
distribute this 'medicine'
freely.

positive use of humour and explained the healthy benefits that are possible including increased blood flow, improved immune response and a better attitude. Moreover, most important, emphasized the effects of a permanent smile. Clowns such as Dr. Fuzy Wuzzy, Dr. Cha Cha, Dr. Floretta Cauliflower and others have introduced children to the skills of administering humour as a medicine. After all we prescribe "Smylenol" rather than Tylenol and have "extra strength Smylenol" for those in troubled smiles.

\section{Chodzinski:}

What might a teacher learn from the clown-doctor program and how could they enhance the classroom experience from this learning?

\section{Warren:}

I believe that teachers are first and foremost caregivers and as such must view the world (their classroom) from a perspective that nurtures and protects each individual in their care and that provides for flexibility and creativity in thinking and doing. This applies to the teacher as well as the student. I find that many teachers focus on the 'illness', what is wrong with a student, what they can't do. They put too much emphasis on curriculum and deliverable outcomes and not enough on the person as a completely unique human being, that is on a student's learning style and individual strengths.

One of the principles that guides all my work is, "Don't think of the problem, think of the solution". I appreciate the pressures of the modern multilingual and multicultural classroom and the 'curriculum imperative' which is placed upon teachers; however I believe it is every teachers' responsibility to try to find ways to reframe each task and reorient or refocus the ways they attempt to accomplish the academic well being of students.

\section{Chodzinski:}

If you were to define your advice in terms of several important points, what would they be?

\section{Warren:}

First, accept what you know and more importantly, what you do not know. Remember all human beings, no matter how young and inexperienced, "know more than they can say". Ultimately, learning needs to be a shared experience! Motivating students to be active partners in their own learning, is both less stressful and more rewarding for everyone.

Practically, first I would say don't forget to breathe... especially when faced with a stress filled situation. Take a step back. Breathe slowly and smoothly, allow each breath to help you relax so that a fresh approach may be nurtured in both thoughts and action.

Then I would say smile. If you smile the muscles in your body will start to relax, and breathing and smiling goes a long way to reducing tension headaches!

I feel teachers need to be a creative detective. They need to learn to read the room, listening with all senses and attention-what the French call "Listening with all antennas up". Do not just look but also learn to see. What I mean is look around and understand the makeup of your classroom. Know who your students are and what they are about.

Learn how to be a flexible responsive teacher. If the lesson is not going as planned, focus on the solution not the problem. Respond not to what you planned for, or expected to happen, but to what you see and hear actually happening. Reflect on what you see; refocus and then adjust the lesson accordingly and try to speak to the students present at that moment in that particular classroom.

Use Humour whenever it helps to 'lighten' the situation and make a 'curriculum moment' come to life. If you feel comfortable doing so tell a joke or a lighthearted anecdote that is in some way connected to the topic or as a means of taking "time out" from the curriculum topic.

\section{Chodzinski:}

In our conversation, you mentioned the importance of a teacher understanding the role of frustration in self-esteem development and that they would do well to think back in time to when they were pupils. Please elaborate. 


\section{Warren:}

If teachers were simply to recall the many times they themselves became frustrated at learning a presented task or encountering a new situation or trying to act healthy when in fact they are not, teachers would be far better prepared to understand the classroom environment on a daily basis and react accordingly. Frustration breeds despair and sadness and contributes to lowered self-esteem which often 'sabotages' the learning process. Teachers should be prepared to provide opportunities for small step learning and small step success building.

\section{Use Humour whenever it helps to 'lighten' the situation and make a 'curriculum moment' come to life.}

It is important for teachers to understand that much stress comes from an inability to express yourself and to be accepted. Anything that assists a child to better express their thoughts or have some say in their environment or personal situation for example school life, hospital life, etc., the more likely they are to be happy and feel a sense of positive self esteem.

Clown-Doctors help people do things that they, in our case patients, thought they might not be able to do or face. In likewise fashion, teachers can emulate the same philosophy and practice. Teachers have the opportunity to work with a known audience. They should use this forum to its best advantage and provide a multitude of opportunities for children to lean how to smile, develop positive self esteem in the face of adversity, and to acquire a repertoire of skills that will help make them resilient when confronted with life challenges.

\section{Chodzinski:}

What reading, resources or Web sites would you suggest that teachers might consult to obtain more information about clown-doctors and more specifically the use of humour in the classroom and in daily life?

\section{Warren:}

There are several excellent websites dealing with clown-doctors and therapeutic humour. Here are a few:

- Fools For Health www.foolsforhealth.ca

- Le Rire Médecin www.leriremedecin.asso.fr/ pages/ch intro.php

- The Humour Foundation: ww.humourfoundation.com.au

- HeartsEMinds www.heartsminds.org.uk

- Association for Applied and Therapeutic Humour www.aath.org

In terms of reading I would suggest beginning with the book that Caroline Simonds and I wrote on the work of Le Rire Médecin:

Simonds, S \& Warren, B (2004) The Clown Doctor Chronicles, Rodopi: Amsterdam \& New York.

People wanting to look a little more deeply may want to read the following:

Warren, B. (2003). Treating Wellness: How clown-doctors help to humanise healthcare and promote good health. In Twohig, P \& Kalitzkus, V (Eds) Making Sense Of Health, Illness And Disease. Rodopi: Amsterdam \& New York pp 201-216

Klein, A (2003) Humor In Children's Lives: A Guidebook For Practitioners, Praeger, Westport, CT.
If people are interested in more information they can also e-mail me at: merv123@uwindsor.ca.

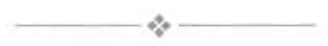

Dr. Bernie Warren is a noted researcher and prolific author and poet. He is currently a full professor

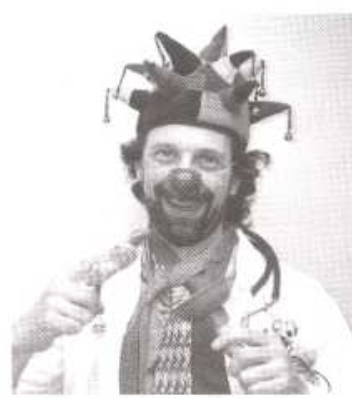
at Windsor University. Prior to coming to Canada, Dr. W a r r e n $\mathrm{t}$ a $\mathrm{u} \mathrm{g} \mathrm{h} \mathrm{t}$ drama and dance in Eng land and Ireland and theatre at the University of Calgary, Antioch, San Francisco and Concordia University. His area of interest is in the role of the arts, drama therapy and healthcare issues. His view that teacher professionals are first caregivers provides a basis on which to apply techniques and stategies for helping students learn. His outstanding work with clown doctors is recognized around the world. He emphasizes humour as a therapeutic intervention. Dr. Warren has received many accolades and awards including the alumni award for distinguished contribution to University Teaching. $\mathrm{He}$ can be reached at merv123@uwindsor.ca or contact him through the Fools for Health web site at www.foolsforhealth.ca.

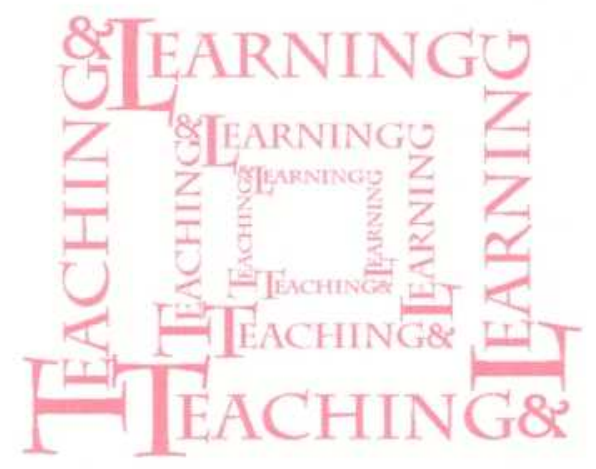

